\title{
Recommendations for Providing Quality Sexually Transmitted Diseases Clinical Services, 2020
}




\section{CONTENTS}

Introduction 1

Methods ..... 3

Current Practice on Selected Clinical Services in the United States ... 5

Recommendations ...6

Future Directions 13

Conclusion

References. 15

\section{Disclosure of Potential Competing Interest}

CDC, the planners, and the presenters disclose they have no financial interests or other relationships with the manufacturers of commercial products, suppliers of commercial services, or commercial supporters with the following exceptions: Kevin Ault, National Institute for Allergy and Infectious Diseases funding; Laura Bachmann, research grants from Cepheid and Melinta; Ronald Goldschmidt, Health Resources and Services Administration (HRSA) funding; Charlene Flash, National Institutes of Health, HRSA, American Medical Association, and Gilead funding; Michael Mugavero, National Institutes of Health, Agency for Healthcare Research and Quality, and Gilead funding.

The MMWR series of publications is published by the Center for Surveillance, Epidemiology, and Laboratory Services, Centers for Disease Control and Prevention (CDC), U.S. Department of Health and Human Services, Atlanta, GA 30329-4027.

Suggested citation: [Author names; first three, then et al., if more than six.] [Title]. MMWR Recomm Rep 2020;68(No. RR-\#):[inclusive page numbers].

\section{Centers for Disease Control and Prevention}

Robert R. Redfield, MD, Director

Anne Schuchat, MD, Principal Deputy Director

Chesley L. Richards, MD, MPH, Deputy Director for Public Health Science and Surveillance

Rebecca Bunnell, PhD, MEd, Director, Office of Science Barbara Ellis, PhD, MS, Acting Director, Office of Science Quality, Office of Science

Michael F. Iademarco, MD, MPH, Director, Center for Surveillance, Epidemiology, and Laboratory Services

\section{MMWR Editorial and Production Staff (Serials)}

Charlotte K. Kent, PhD, MPH, Editor in Chief Christine G. Casey, MD, Editor

Mary Dott, MD, MPH, Online Editor

Terisa F. Rutledge, Managing Editor

David C. Johnson, Lead Technical Writer-Editor Marella Meadows, Project Editor

Ileana Arias, $\mathrm{PhD}$

Matthew L. Boulton, MD, MPH

Jay C. Butler, MD

Virginia A. Caine, MD

Katherine Lyon Daniel, PhD
MMWR Editorial Board Timothy F. Jones, MD, Chairman Jonathan E. Fielding, MD, MPH, MBA David W. Fleming, MD

William E. Halperin, MD, DrPH, MPH Jewel Mullen, MD, MPH, MPA Jeff Niederdeppe, PhD Patricia Quinlisk, MD, MPH
Martha F. Boyd, Lead Visual Information Specialist Maureen A. Leahy, Julia C. Martinroe, Stephen R. Spriggs, Tong Yang, Visual Information Specialists

Quang M. Doan, MBA, Phyllis H. King, Terraye M. Starr, Moua Yang, Information Technology Specialists

Stephen C. Redd, MD

Patrick L. Remington, MD, MPH

Carlos Roig, MS, MA

William Schaffner, MD

Morgan Bobb Swanson, BS 


\title{
Recommendations for Providing Quality Sexually Transmitted Diseases Clinical Services, 2020
}

\author{
Roxanne Y. Barrow, $\mathrm{MD}^{1}$; Faruque Ahmed, $\mathrm{MD}, \mathrm{PhD}^{1}$; Gail A. Bolan, $\mathrm{MD}^{1}$; Kimberly A. Workowski, MD ${ }^{1,2}$ \\ ${ }^{1}$ Division of STD Prevention, National Center for HIVIAIDS, Viral Hepatitis, STD, and TB Prevention, CDC; ${ }^{2}$ Emory University, Atlanta, Georgia
}

\begin{abstract}
Summary
This report (hereafter referred to as STD QCS) provides CDC recommendations to U.S. health care providers regarding quality clinical services for sexually transmitted diseases (STDs) for primary care and STD specialty care settings. These recommendations complement CDC's Sexually Transmitted Diseases Treatment Guidelines, 2015 (hereafter referred to as the STD Guidelines), a comprehensive, evidence-based reference for prevention, diagnosis, and treatment of STDs. STD QCS differs from the STD Guidelines by specifying operational determinants of quality services in different types of clinical settings, describing on-site treatment and partner services, and indicating when STD-related conditions should be managed through consultation with or referral to a specialist. These recommendations might also help in the development of cliniclevel policies (e.g., standing orders, express visits, specimen panels, and reflex testing) that can facilitate implementation of the STD Guidelines. CDC organized the recommendations for STD QCS into eight sections: 1) sexual history and physical examination, 2) prevention, 3) screening, 4) partner services, 5) evaluation of STD-related conditions, 6) laboratory, 7) treatment, and 8) referral to a specialist for complex STD or STD-related conditions.

CDC developed the recommendations by synthesizing relevant, evidence-based guidelines and recommendations issued by other experts; reviewing current practice in the United States; soliciting Delphi ratings by subject matter experts on STD care in primary care and STD specialty care settings; discussing the scientific evidence supporting the proposed recommendations at a consultation meeting of experts and institutional stakeholders held November 20, 2015, in Atlanta, Georgia; conducting peer reviews of draft recommendations and supporting evidence; and discussing draft recommendations and supporting evidence during meetings of the CDC/Health Resources and Services Administration Advisory Committee on HIV, Viral Hepatitis, and STD Prevention and Treatment STD Work Group. These recommendations are intended to help health care providers in primary care or STD specialty care settings offer STD services at their clinical settings and to help the persons seeking care live safer, healthier lives by preventing and treating STDs and related complications.
\end{abstract}

\section{Introduction}

\section{Background}

Approximately 20 million new cases of sexually transmitted diseases (STDs) occur every year in the United States, with approximately half occurring among persons aged 15-24 years (1). In recent years, STDs rates have increased (2). STDs account for $\$ 16.9$ billion annually in health care costs (3). STDs can lead to severe reproductive health complications, such as infertility, ectopic pregnancy, and congenital infection. In addition, STDs can increase a person's risk for acquiring and transmitting human immunodeficiency virus (HIV) infection $(4,5)$.

Corresponding author: Roxanne Barrow, MD, National Center for HIV/AIDS, Viral Hepatitis, STD, and TB Prevention, CDC. Telephone: 404-639-8503; E-mail: rbarrow@cdc.gov.
STDs increasingly are being diagnosed in various health care settings. Most reported STD cases are from providers in non-STD clinics, such as private physician offices and community health centers (2). Historically, STDs were diagnosed in public health clinics for reasons of anonymity, confidentiality, and specialized care. A principle of STD care is timely management of infections, evidenced by the Brussels Agreement of 1924, an international treaty that sought to establish STD care in ports for merchant marines (6). In the United States, clinics dedicated to caring for patients with STDs, such as the first STD clinic in Baltimore, Maryland, which opened in 1922, offered confidential care to counteract the stigma of syphilis ( 7 ). These types of clinics increased in number during the 1930s and 1940s, and clinics have remained a large component of public health services (8). The framework for these STD clinics included timely diagnosis, testing with on-site treatment, and partner services. 
During the 1980s and 1990s, most specialized STD care was provided in STD clinics and HIV programs (9). For patients, STD clinics were unique because they provided confidential, walk-in, low-cost specialty care (9) and offered the expertise necessary to manage STDs (10). However, because of funding issues, public health services and the number of STD clinics were reduced substantially during 2008-2012. Approximately half of local health departments reported reduction or elimination of at least one program, such as clinical health services or communicable disease screening and treatment, because of funding (11) and at least $10 \%$ of STD clinics closed (12).

Over time and with decreased availability of STD clinics, patients have sought care for STDs at primary care clinics, emergency departments, and family planning clinics (13). Primary care providers are an important component of sexual health care because many patients with STDs are asymptomatic and their infections might be identified while receiving services in the primary care setting. Certain studies have found that primary care clinics might diagnose up to half of reported STDs (13). In 2018, 71\%-80\% of STD cases were reported from non-STD clinics (5). One study that examined patients' choice of providers for STD care found that, with expanded health care insurance coverage, patient visits to primary care providers increased more than $100 \%$ and STD clinic visits decreased $20 \%$. This increase in primary care visits was largely attributable to a rise in the percentage of women seen for STD care (14). Despite these shifts in settings for STD service provision, publicly funded STD clinics continue to serve as a safety net for patients without insurance coverage or other marginalized groups of patients seeking care (15).

\section{Rationale}

With increasing rates of most STDs in recent years (2), all providers have a role in the assessment of STD risk and management of infections. STD clinics will continue to be locations of expert care and are increasingly recognized as venues to provide HIV preexposure prophylaxis (PrEP) to prevent incident HIV infections (16). Providers in primary care offices, family planning clinics, and community-based clinics will continue to diagnose STDs among asymptomatic patients who are especially at risk for STDs. Recommendations for operationalizing STD care in health care settings are needed because provision of STD services varies. This report (hereafter referred to as STD QCS) describes what constitutes quality STD clinical services in primary care and STD specialty care settings.

In this report, provision of STD care is described as basic or specialized. Basic STD care usually is provided in primary care settings where patients are seen for various health conditions.
Typically, specialized STD care is delivered in STD specialty care settings that focus on providing timely, comprehensive, confidential, and culturally sensitive STD care. Patients with STD-related conditions beyond the scope of both primary care and STD specialty care settings, such as those needing advanced diagnostics (e.g., lumbar punctures or ocular evaluations) or inpatient care, should be managed through consultation with or referral to a specialist.

CDC's Sexually Transmitted Diseases Treatment Guidelines, 2015 (hereafter referred to as the STD Guidelines) provides clinical guidance to physicians and other health care providers on the prevention, diagnosis, and treatment of STDs in the United States (17). The recommendations in STD QCS are intended to complement the STD Guidelines; as such, the STD Guidelines has not been modified. Rather, this report provides guidance on clinical operations and the types of services that should be available for STD care. STD QCS describes optimal services for the provision of quality STD-related clinical care by setting, including services that should be available at the time of the patient visit. Availability of same-day, on-site tests can reduce diagnostic delays and decrease excessive and costly presumptive treatment (18). On-site medications for STDs can minimize the duration of infectiousness and reduce STD transmission, decrease the cost of staff needed to follow up on positive tests and verify treatment, and lessen complications in the interval between testing and return visits for therapy $(19,20)$. In settings where patient return rates are inconsistent, same-day services might result in more cases being diagnosed and more patients receiving timely treatment (21). Same-day treatment for patients and their sex partners is also critical for STD prevention and control because it can reduce transmission of STDs in the community.

In the Institute of Medicine* report Crossing the Quality Chasm: A New Health System for the 21st Century, the framework for health care quality was outlined using the following six domains: 1) safety, 2) effectiveness, 3) patient centeredness, 4) timeliness, 5) efficiency, and 6) equity (22). These domains are essential for the provision of quality STD clinical care services:

1. Safety: Patient safety includes the physical health care environment; seamless clinic processes; knowledge of the patients' care plan; confidential services, especially confidential partner services; and an informed patient $(22,23)$.

2. Effectiveness: Effective care includes providing services that are consistent with recognized medical and laboratory guidelines.

\footnotetext{
* The name of the Institute of Medicine was changed to the National Academy of Medicine, effective July 1, 2015 (http://www.nationalacademies.org/hmd/ Global/News\%20Announcements/IOM-to-become-NAM-Press-Release.aspx).
} 
3. Patient centeredness: A patient-centered approach ensures

- patient confidentiality,

- attention to issues that disproportionally affect vulnerable populations,

- guaranteeing a friendly and welcoming environment through cultural sensitivity,

- a seamless referral process between health care providers, and

- delivery of information and education relevant to a patient's diagnosis, treatment, prognosis, and prevention measures.

4. Timeliness: Key factors in ensuring that services are provided in a timely manner include availability, accessibility, acceptability, and visibility of services (e.g., facility location, hours of operation, waiting time until appointment, waiting time in the clinic, staffing levels, and facility space); availability and selection of laboratory technologies and turnaround times for laboratory procedures; availability, accessibility, and cost of treatments; and availability of partner management and other prevention services, such as condoms and behavioral counseling $(18,23)$. Timely and appropriate STD management can be influenced by several factors, including

- patient health care-seeking behaviors,

- diagnostic capabilities,

- treatment capabilities, and

- prevention activities.

5. Efficiency: An efficient health care system optimizes its resources by improving safety, effectiveness, patient centeredness, and timeliness.

6. Equity: Equity in health care ensures universal access to quality care.

\section{Scope and Audience}

The recommendations in STD QCS apply to private and public providers of STD clinical services, including those in primary care settings (e.g., internal medicine, family medicine, or obstetrics-gynecology private offices; school-based health or community health centers; correctional health care settings; or HIV-care clinics) as well as those in sites dedicated to STD service delivery (e.g., STD or sexual health clinics). The focus is on structural-level policy recommendations about which STD-related clinical services should be available to facilitate implementation of the STD Guidelines.

In addition to these providers, STD QCS can also be used by others, such as

- medical directors to develop protocols that outline clinic procedures for delivering STD care,
- public health officials to establish partnerships with local care providers to reduce STD clinical service gaps,

- community organizations to stay informed about expected STD services for clients,

- health care administrators to measure or monitor health care facilities' adherence to national recommendations,

- health care professionals and patients to advocate for quality services, and

- health care organizations to develop quality measures for STD services.

STD QCS recommendations address the following questions:

- What STD-related clinical services should be available to persons who have or are at risk for STDs, including asymptomatic persons, in primary care settings?

- What STD-related clinical services should be available to persons who have or are at risk for STDs in STD specialty care settings?

- Which STD-related conditions should be managed through consultation with or referral to a specialist?

These recommendations allow health care providers to build, maintain, or enhance the delivery of STD services in their primary care and STD specialty care settings. STD QCS is not intended to develop new guidance for when or how to provide the services or to mandate or regulate services. Health care settings might not provide every service outlined for quality STD care; however, the recommendations can provide the opportunity to assess which services are available in a facility and determine whether additional services can or should be made available or whether mechanisms for referral can or should be developed.

\section{Methods}

\section{Overview}

CDC developed these recommendations after consultation with a wide range of experts and stakeholders. CDC took into account existing national guidelines and recommendations, current practice in the United States, Delphi ratings by subject matter experts (SMEs) on STD care in primary care and STD specialty care settings followed by discussion at a consultation meeting, input of external private providers, and feedback from the CDC/Health Resources and Services Administration (HRSA) Advisory Committee on HIV, Viral Hepatitis, and STD Prevention and Treatment (CHAC).

In January 2015, CDC formed a steering committee that defined the scope of the proposed recommendations and provided feedback to CDC on the development process. SMEs on STD care in primary care and STD specialty care settings met via conference calls during 
June-September 2015 to provide individual feedback to CDC on the proposed recommendations. CDC developed draft recommendations that were discussed at a consultation meeting held November 20, 2015, in Atlanta, Georgia. The meeting included members of the steering committee, SMEs, federal agencies (i.e., CDC, Office of Population Health, and HRSA), and other stakeholders. Participants at the consultation meeting gave individual feedback on these draft recommendations. CDC sought additional input on the draft recommendations from private providers identified by stakeholders representing professional organizations (i.e., American Academy of Family Physicians [AAFP], American Academy of Pediatrics [AAP], American Congress of Obstetricians and Gynecologists [ACOG], and American College of Physicians [ACP]). Four private providers from AAFP provided input. Proposed revisions from CHAC were presented and approved at the October 2017 CHAC meeting in Rockville, Maryland.

All CDC staff, steering committee members, SMEs, and consultation meeting participants disclosed potential competing interests. CHAC and CHAC STD Work Group members also disclosed potential competing interests.

\section{Literature Review}

Recommended STD-related clinical services were identified by reviewing relevant evidence-based guidelines and recommendations, including recommendations from the STD Guidelines, the Advisory Committee on Immunization Practices (ACIP), AAP, ACOG, the British Association for Sexual Health and HIV, the World Health Organization, and the U.S. Preventive Services Task Force (Supplementary Appendix 1, https://stacks.cdc.gov/view/cdc/82088). A systematic literature search also was conducted to identify current practice for STD screening in the United States (Supplementary Appendix 2, https://stacks.cdc.gov/view/cdc/82088). Medline and PsycInfo databases were searched for studies published from January 1 , 1985, through May 26, 2015, and the Sexually Transmitted Diseases journal was searched from January 2006 through October 2015. Articles were screened using titles, and 414 abstracts and relevant full-text articles were retrieved. The reference lists of included studies were reviewed and the SMEs provided additional relevant citations (Supplementary Appendix 3, https://stacks.cdc.gov/view/cdc/82088). The inclusion criteria were articles describing original studies or systematic reviews that were published in English and that included U.S. populations or settings. Commentaries, letters, and editorials were excluded.

\section{Delphi Process}

Using a modified Delphi process (a method that solicits the opinions of experts through a series of questionnaires), participating SMEs gave input on what clinical services should be available as basic and specialized STD care services (24). An online Delphi rating form, developed by CDC using SurveyMonkey, included definitions or indications for the clinical services. Discussions of the Delphi ratings were conducted (two rounds by the SMEs on STD care in primary care settings and three rounds by the SMEs on STD care in STD specialty care settings) with structured conference calls led by a moderator to obtain comments. The Delphi forms were modified on the basis of discussions during the conference calls. Aggregate results and comments were reviewed and discussed during the conference calls. Nine members of the primary care setting panel and nine members of the STD specialty care setting panel completed the ratings. The most important criteria for rating the clinical services was the association with quality of STD care and the feasibility of having a service available. SME panel members rated each clinical service on the basis of their clinical experience. Each service was rated using a scale from one to nine, where one indicated disagreement with the statement and nine indicated agreement. Median and dispersion of the ratings were analyzed to prioritize the clinical services, which were classified as appropriate (median rating of 7-9 without disagreement), inappropriate (median rating of 1-3 without disagreement), or uncertain (median rating of 4-6, or any median with disagreement). Disagreement was defined as at least three of the nine panelists rating a service outside the three-point region containing the median. A summary of the rating results is available (Supplementary Appendix 4, https://stacks.cdc.gov/view/cdc/82088).

\section{Federal Advisory Committee Review and Findings}

CHAC is a federal advisory committee that advises the U.S. Department of Health and Human Services secretary, CDC director, and HRSA administrator about objectives, strategies, policies, and priorities for HIV, viral hepatitis, and STD prevention and treatment efforts. At the May 2017 CHAC meeting, the committee approved establishment of the CHAC STD Work Group to review and provide feedback on the CDC draft recommendations. The CHAC STD Work Group consisted of 17 SMEs from the public and private sectors. The work group met four times by telephone during August-September 2017 to review and discuss proposed 
revisions from individual members. The summary report was presented and approved at the October 2017 CHAC meeting. CHAC submitted a letter to the CDC director and the HRSA administrator outlining their findings.

\section{Recommendation Format}

Recommendations are presented as described in the Grading of Recommendations Assessment, Development, and Evaluation (GRADE) (25). Strong recommendations are worded as "should" and weak recommendations are worded as "could." A strong recommendation implies that all or almost all informed providers would choose the recommended course of action. A weak recommendation indicates that most informed providers would choose the recommended course of action but some would not. Delphi ratings were used to guide the development of recommendations, and clinical services reviewed were classified as appropriate, uncertain, or inappropriate and were worded as "should," "could," or "would not be expected," respectively.

Current practice, discussion at the consultation meeting, and CHAC findings also were considered in formulating the strength of the recommendations. The specific guidance for prevention strategies, screening, diagnosis, and treatment are discussed briefly. More comprehensive information is available in the STD Guidelines and other references therein.

\section{Current Practice on Selected Clinical Services in the United States}

STDs can be prevented using various strategies, including male latex condoms, behavioral counseling, preexposure vaccination, and presumptive treatment after exposure. Timely and appropriate treatment of persons with STDs is critical for reducing transmission and preventing complications. Prevention and timely treatment of STDs depend on several factors, including taking a sexual history, assessing risk for STDs, performing screening and diagnostic testing, providing on-site medications, and notifying and managing sex partners (18).

Obtaining a sexual history and assessing risk for STDs include the five Ps (i.e., partners, practices, protection, past STDs, and prevention of pregnancy) (17). Most primary care providers obtain a sexual history if it is relevant to the chief complaint but less frequently at an initial or routine annual visit and seldom at acute care, non-STD-related visits (26-32). Adolescent medicine clinicians, pediatricians, and obstetricians-gynecologists are more likely to regularly take a sexual history than family medicine clinicians, general practitioners, and internists $(26,28,29,33)$. Primary care providers most commonly inquire about sexual activity and history of STDs but less often ask about the number of sex partners, gender of sex partners, and specific sexual practices (oral, vaginal, or anal sex) $(27,29,34,35)$. Several studies have determined that STD clinics obtain more complete sexual histories than primary care clinics $(36,37)$.

Screening and diagnostic testing are important to detect asymptomatic or confirm suspected infections. Previous studies have documented that one third to one half of primary care clinicians routinely screen men or women for STDs (chlamydia, gonorrhea, syphilis, or HIV) $(26,33,38,39)$. Obstetriciansgynecologists screen nonpregnant women more often than other primary care physicians (39-41). Community health centers often provide routine HIV testing for pregnant women but less frequently offer routine HIV testing for men and nonpregnant women $(42,43)$. Some emergency departments perform routine HIV testing, although the practice is not widespread (44). For correctional settings, routine testing varies by type of facility. State and federal prison systems commonly perform routine syphilis testing at intake but less often offer routine testing for HIV, gonorrhea, or chlamydia (45). Some city and county prisons conduct routine testing for syphilis but rarely offer routine testing for HIV, gonorrhea, or chlamydia (45). Jails and juvenile detention centers infrequently offer routine testing for STDs and rarely perform routine HIV testing $(46,47)$.

In primary care clinics, Gram stain testing for gonorrhea usually is not performed on site because of difficulty obtaining Clinical Laboratory Improvement Amendments (CLIA) certification (48). Among 15 publicly funded STD clinics participating in the STD Surveillance Network, testing for Trichomonas vaginalis rarely involved culture, rapid antigen testing, or nucleic acid amplification test (NAAT); testing was almost exclusively performed using wet mount microscopy (49). A national survey of public health laboratories reported that only one fourth performed direct detection for syphilis. However, most laboratories conducted serological testing for syphilis (50). A survey of laboratories in the District of Columbia that reported gonorrhea results to the health department demonstrated that among laboratories that conducted gonorrhea cultures, only one third performed antibiotic susceptibility testing (51). A study of clinical laboratories in California reported that gonorrhea culture testing has substantially decreased and gonorrhea and chlamydia tests performed using NAAT have increased over time (52). For detection of herpes simplex virus (HSV), direct antigen and culture testing on lesions have decreased over time and serologic testing has increased (52).

If an infected patient receives timely treatment at an initial visit, further transmission can be interrupted. In one study, uninsured young adults were three to four times more likely to 
not fill a prescription (53). A study of primary and secondary syphilis cases reported to the Arizona STD Control Program indicated that treatment at the initial visit occurred more frequently for STD clinic patients compared with non-STD clinic patients $(57 \%$ versus $8 \%)(54,55)$. A study of gonorrhea cases reported to the Philadelphia Department of Public Health indicated that among the 3,279 cases with documented treatment, $44 \%$ of the patients received same-day treatment. The median time to treatment for patients not treated the same day was 8 days (56). Among 1,241 patients with positive gonorrhea or chlamydia screening cultures who did not receive empiric treatment at their initial visit at an STD clinic in Alabama, 251 (20\%) did not return to the clinic for treatment within 30 days of screening (57). Among 165 female patients with positive chlamydia tests who did not receive empiric treatment at their initial visit at a university medical center in Alabama, 55 (33\%) emergency department or walk-in clinic patients and $14(8 \%)$ obstetrics-gynecology patients had no treatment documented (58). A study of insured patients in 50 states indicated that $10 \%$ of new prescriptions for STD antimicrobials were not filled (59).

Notifying and treating sex partners interrupts transmission, prevents reinfection, and might prevent complications from unrecognized infections. Studies demonstrate that most primary care clinicians instruct patients with STDs to notify their sex partners for evaluation and treatment $(39,60-63)$. Certain studies have found that approximately $50 \%$ of primary care clinicians reported ever having used expedited partner therapy (EPT) for chlamydia or gonorrhea but a substantially lower proportion $(6 \%-27 \%)$ reported always or usually using this practice $(61,62,64,65)$. Obstetricians-gynecologists and family medicine physicians reported using EPT more often than internal medicine physicians $(63,64)$. A survey of community health centers in Indiana reported that $61 \%$ told patients with gonorrhea or chlamydia to refer their partner for testing and treatment and 18\% always gave medication to patients to distribute to their partners (66). A survey of Federally Qualified Health Centers in New York City reported that $80 \%$ provided EPT for chlamydia, of which $47 \%$ were by prescription only, $27 \%$ by both prescription and dispensed medication, and $6 \%$ by dispensed medication only (67). A survey of family planning clinics in California found that $19 \%$ of partners received patient-delivered partner therapy (PDPT) and $55 \%$ received a patient referral. However, report of the partner receiving the treatment was higher for PDPT (80\%) than for patient referral $(44 \%)(68,69)$.

\section{Recommendations}

STD QCS recommendations are outlined in the following eight sections: 1) sexual history and physical examination, 2) prevention, 3) screening, 4) partner services, 5) evaluation of STD-related conditions, 6) laboratory, 7) treatment, and 8) referral to a specialist for complex STD or STD-related conditions. Boxes 1-7 include the recommendations for basic STD care and specialized STD care. Citations of official guidelines and studies that support these recommendations accompany each section of recommendations. Box 8 includes a list of complex STD or STD-related conditions that primary care and STD specialty care settings should refer to a specialist.

\section{Sexual History and Physical Examination}

A sexual history and risk assessment are foundational to providing quality STD care services $(17,70,71)$. A complete sexual history includes inquiring about the five Ps (i.e., partners, practices, protection, past history of STDs, and prevention of pregnancy) (17). A Guide to Taking a Sexual History is available (https://www.cdc.gov/std/treatment/sexualhistory.pdf). The sexual history and risk assessment should be available as part of an initial comprehensive or annual visit; a visit for reproductive, genital, or urologic issues; or a visit for STD-related symptoms, STD-related concerns, or concerns about preventing or achieving pregnancy. The sexual history and risk assessment might be provided during an HIV, PrEP, or acute care visit.

A physical examination for STDs includes inspection of the skin, pharynx, lymph nodes, anogenital area, and neurologic system. The examination can provide useful information among males and females with STD-related symptoms (17,70-73). A physical examination allows health care providers the opportunity to identify the presence of any signs of STDs of which a patient might or might not be aware.

An anogenital examination for females includes a pelvic examination with three elements: 1) inspection of the external genitalia, urethral meatus, vaginal introitus, and perianal region; 2) speculum examination of the vagina and cervix; and 3) bimanual examination of the uterus, cervix, and adnexa (72). A colposcopy might be a useful procedure to examine the cervix, vagina, and vulva more closely for signs of disease and is recommended for those patients with abnormal Papanicolaou smear tests (Pap smears) according to the American Society for Colposcopy and Cervical Pathology (https:/www.ncbi.nlm.nih.gov/pmc/articles/PMC3801360). An anogenital examination for males includes an external genital examination and inspection of the penis, scrotum, scrotal contents, and perianal region (74). An anoscopy can assist with the visualization of the anal canal among patients with rectal symptoms or history of receptive anal intercourse. 
Sexual history and physical examination recommendations are summarized (Box 1). Additional information on sexual history and physical examination recommendations is available (Supplementary Appendix 1, https://stacks.cdc.gov/view/cdc/82088).

\section{Prevention}

Services for preventing STDs and related conditions, including HIV, consist of eight strategies. These are 1) condom provision $(17,70,75)$; 2) hepatitis A vaccination $(17,76)$; 3) hepatitis $B$ vaccination $(17,77)$; 4) human papillomavirus (HPV) vaccination $(78,79)$; 5) emergency contraceptive pills $(17,80,81)$; 6) STD/HIV prevention counseling (brief, moderate intensity, or high intensity) $(17,82-84)$; 7) PrEP for HIV prevention risk assessment, education, counseling, provision, and linking or referral, or both (85); and 8 ) nonoccupational postexposure prophylaxis (nPEP) of HIV risk assessment, education, counseling, provision, and linking or referral, or both, to HIV care (86).

STD/HIV prevention counseling, including behavioral counseling methods, can be used by health care providers to effect patient changes to reduce the patient's risk for STD acquisition and transmission. The methods vary in scope and time. Brief prevention counseling is conducted in a single session using strategies, such as motivational interviewing and building rapport, and includes patient circumstances and needs in the counseling plan. Moderate-intensity and high-intensity behavioral counseling is contact time of 30-120 minutes and $\geq 2$ hours, respectively (82). Contraceptive counseling enables clients to make and follow through on decisions about their contraceptive use. Education is an integral component of the contraceptive counseling process and helps clients make informed decisions and obtain information needed to use contraceptive methods correctly. Guidance for clinical providers on contraceptive services are outlined in Providing Quality Family Planning Services: Recommendations of CDC and the U.S. Office of Population Affairs (87). Linkage to care and helping patients start HIV medical care shortly after diagnosis can enhance prompt delivery of important services and support efforts to eliminate HIV infection (83). Linkage to HIV care, family planning, and behavioral health services can increase the proportion of those living with HIV who are virally suppressed, reduce unintended pregnancies, and maximize long-term behavioral health. Guidance for clinical providers on linkage to and retention in HIV medical care is outlined in the Recommendations for HIV Prevention with Adults and Adolescents with HIV in the United States, 2014 Summary for Clinical Providers (88).

Prevention recommendations are outlined (Box 2). Additional information on prevention recommendations is available (Supplementary Appendix 1, https://stacks.cdc.gov/ view/cdc/82088).

BOX 1. Recommendations for obtaining a sexual history and conducting a physical examination as part of sexually transmitted diseases care in primary care and sexually transmitted diseases specialty care settings*

\section{STD care in primary care settings}

- A sexual history and risk assessment should be available as part of basic STD care services at the following patient visits:

- Initial comprehensive or annual visit

- Each visit concerning reproductive, genital, or urologic issues

- A physical examination should be available as a basic STD care service for male and female patients with STD-related symptoms, STD-related concerns, or those at high behavioral risk for incident STDs.

- A pelvic examination should be available as a basic STD care service.

- A sexual history and risk assessment could be available as basic STD care services at each visit unrelated to reproductive, genital, or urologic concerns.

- Anoscopy could be available as a basic STD care service.

\section{STD care in STD specialty care settings}

- A sexual history and risk assessment should be part of specialized STD care services at every visit for patients with STD-related symptoms, STD-related concerns, or concerns about preventing or achieving pregnancy.

- A physical examination should be available as a specialized STD care service for male and female patients with STD-related symptoms, STD-related concerns, or high behavioral risk for incident STDs.

- A pelvic examination should be available as a specialized STD care service.

- Colposcopy should be available as a specialized STD care service for female patients with abnormal Pap smears.

- Anoscopy should be available as a specialized STD care service.

- A high-resolution anoscopy could be available as a specialized STD care service for patients with abnormal anal Pap smears.

Abbreviations: Pap = Papanicolaou; STD = sexually transmitted disease.

* Primary care setting is defined as a place where patients are evaluated for various health conditions. An STD specialty care setting is defined as a place where the focus is on providing patients with timely, comprehensive, confidential, and culturally sensitive STD care. STD care delivered in STD specialty care settings includes all care delivered in primary care settings. 


\section{STD care in primary care settings}

- The following prevention services should be available as basic STD care services:

- On-site hepatitis B vaccination or referral

- On-site HPV vaccination or referral

- Brief single STD/HIV prevention counseling session (up to 30 minutes) ${ }^{\dagger}$

- PrEP for HIV prevention and nPEP of HIV risk assessment, education, and referral or link to HIV care ${ }^{\dagger}$

- Emergency contraceptive pills $\$$

- Brief contraceptive counseling or referral

- Referral or link to HIV care, family planning services, and behavioral health services, if indicated

- The following prevention services could be available as basic STD care services:

- On-site condom provision

- On-site hepatitis A vaccination

- Provision of PrEP for HIV prevention**

- Provision of nPEP of $\mathrm{HIV}^{\dagger \dagger}$

- Moderate-intensity STD behavioral counseling $(\geq 30 \text { minutes })^{\dagger}$

\section{STD care in STD specialty care settings}

- The following prevention services should be available as specialized STD care services:

- On-site condom provision

- On-site hepatitis A vaccination

- On-site hepatitis B vaccination

- On-site HPV vaccination

- Brief single STD/HIV prevention counseling session (up to 30 minutes) ${ }^{\dagger}$

- PrEP for HIV prevention and nPEP of HIV risk assessment, education, counseling, and referral or link to HIV care $^{\dagger}$

- Provision of PrEP for HIV prevention $\$ \$$

- Provision of nPEP of HIV 9

- Brief contraceptive counseling or referral

- Emergency contraceptive pills $\$$

- Referral or link to HIV care, family planning services, and behavioral health services, if indicated

- The following prevention services could be available as specialized STD care services:

- Moderate-intensity STD behavioral counseling $(\geq 30 \text { minutes })^{\dagger}$

- High-intensity STD behavioral counseling $(\geq 2 \text { hours })^{\dagger}$

Abbreviations: $\mathrm{HIV}=$ human immunodeficiency virus; $\mathrm{HPV}=$ human papillomavirus; $\mathrm{nPEP}=$ nonoccupational postexposure prophylaxis; $\mathrm{PrEP}=$ preexposure prophylaxis; STD = sexually transmitted disease.

* Primary care setting is defined as a place where patients are evaluated for various health conditions. STD specialty care setting is defined as a place where the focus is on providing patients with timely, comprehensive, confidential, and culturally sensitive STD care. STD care delivered in STD specialty care settings includes all care delivered in primary care settings.

$\dagger$ Provided by a clinician or other appropriately trained staff.

$\$$ If emergency contraceptive pills are not available on site or by prescription, patients can be advised that levonorgestrel emergency contraceptive pills are available over the counter and ulipristal acetate emergency contraceptive pills are only available by prescription. Emergency contraceptive pills should be taken as soon as possible within 5 days of unprotected sex.

9 Providers can partner with local organizations, such as the local health department and community-based organizations, to procure condoms. In some states, prescriptions can be written for condoms. For certain settings, such as family planning clinics, condoms should be available on site.

** PrEP could be available by starter packs or prescription with on-site follow-up care for basic STD care. If PrEP is not provided, navigator-assisted referral for PrEP should be provided with first appointment made while the patient is on site.

$\dagger \dagger$ nPEP starter pack (3-7 days of medication) could be available on site, with either on-site follow-up care or referral for basic STD care. nPEP starter pack or complete 28-day course could be available by prescription, with either on-site follow-up care or referral, with first appointment made while the patient is on site. Provision of the complete 28-day nPEP medication supply at the initial visit rather than a starter pack of 3-7 days has been reported to increase likelihood of adherence, especially when patients find returning for multiple follow-up visits difficult. Routinely providing starter packs or the complete 28 -day course requires that health care providers stock nPEP drugs in their practice setting or have an established agreement with a pharmacy to stock, package, and urgently dispense nPEP drugs with required administration instructions (https://www.cdc.gov/hiv/pdf/programresources/cdc-hiv-npep-guidelines.pdf).

$\$ \$$ PrEP should be available in starter packs or by prescription with on-site follow-up care for specialized STD care. If PrEP is not provided, navigator-assisted referral for PrEP should be provided with first appointment made while the patient is on site.

99 nPEP starter pack (3-7 days of medication) should be available on site, with either on-site follow-up care or referral to specialized STD care. nPEP complete 28-day course should be available by prescription, with either on-site follow-up care or referral, with first appointment made while the patient is on site. Provision of the complete 28-day nPEP medication supply at the initial visit rather than a starter pack of 3-7 days has been reported to increase likelihood of adherence, especially when patients find returning for multiple follow-up visits difficult. 


\section{Screening}

Screening for asymptomatic STDs is important for early detection and prevention of STDs. Because many STDs are asymptomatic, testing is the only method to diagnose these infections. The availability of screening tests are key for identifying gonorrhea, chlamydia, syphilis, hepatitis B, hepatitis $\mathrm{C}, \mathrm{HIV}$, trichomoniasis, and cervical and anal cancer (17,84,89-99). Results from these screening tests can be used to identify persons at risk for STDs (17). Data are insufficient to recommend routine anal cancer screening with anal cytology among persons with HIV infection, men who have sex with men (MSM) without HIV infection, and the general population (17). However, some clinical centers perform anal cytology to screen for anal cancer among high-risk populations followed by a high-resolution anoscopy for those with abnormal cytologic results. Colposcopy is a recommended tool for cervical cancer screening.

A table summarizing screening recommendations for women, pregnant women, men, MSM, and persons with HIV is available (https://www.cdc.gov/std/treatment-guidelines/). Recommendations for STD screening are listed (Box 3). Additional information on screening recommendations is available (Supplementary Appendix 1, https://stacks.cdc.gov/ view/cdc/82088).

\section{Partner Services}

Treatment of sex partners prevents reinfection and is essential to interrupting transmission of STDs. Partner services consist of various strategies with differing levels of time and effort to enable persons who are exposed to an STD to be identified, tested, and treated. These strategies include 1) guidance regarding notification and care of sex partners, 2) interactive counseling for partner notification, 3) EPT, and 4) health department disease intervention specialist (DIS) elicitation of sex partner information to identify those who might be infected and to identify patient follow-up needs $(17,83,100-106)$.

Guidance regarding notification and care of sex partners is described as providers giving how-to information to their patients about the need to notify their sex partner or partners of the exposure, the need for sex partners to seek care and treatment even if they do not have symptoms, and where a partner could go for STD care. This strategy typically does not require extensive staff training. Guidance might be verbal or written. When notifying patients of an STD diagnosis and need to return for treatment, providers can advise patients to bring their sex partner with them, at which time the provider should treat both persons concurrently (69).

In interactive counseling, the provider and patient both actively participate in an individualized plan to notify the patient's sex partner or partners. Interactive counseling typically is conducted by staff with specific training or skills in communication, interviewing, or counseling. The patient provides information about their sex partner or partners and develops a plan with the counselor to notify partners. Notification might involve the patient, the provider, or the health department. Efforts to notify partners can be documented and assessed.

BOX 3. Screening recommendations for sexually transmitted diseases care in primary care and sexually transmitted diseases specialty care settings*

\section{STD care in primary care settings}

- Screening and assessment for the following STDs should be available as basic STD care services:

- Gonorrhea

- Chlamydia

- Syphilis

- Hepatitis B

- Hepatitis C

o HIV

- Cervical cancer

- Screening and assessment for the following STD could be available as a basic STD care service:

- Trichomoniasis

\section{STD care in STD specialty care settings}

- Screening and assessment for the following STDs should be available as specialized STD care services:

- Gonorrhea

- Chlamydia

- Syphilis

- Hepatitis B

- Hepatitis C

- HIV

- Cervical cancer

- Trichomoniasis

- Screening and assessment for the following STD could be available as a specialized STD care service:

- Anal cancer

Abbreviations: $\mathrm{HIV}=$ human immunodeficiency virus; $\mathrm{STD}=$ sexually transmitted disease.

* Primary care setting is defined as a place where patients are evaluated for various health conditions. STD specialty care setting is defined as a place where the focus is on providing patients with timely, comprehensive, confidential, and culturally sensitive STD care. STD care delivered in STD specialty care settings includes all care delivered in primary care settings. 
EPT typically is recommended for sex partners of patients who have received a diagnosis of chlamydia or gonorrhea, or both, and who are unlikely to access timely care. This is a method that provides medications or prescriptions to the patient to take to a partner without the partner first being examined by a health care provider. EPT is legislated or regulated at the state level, and what each state allows can vary by STD, age group, and sexual orientation. Details about EPT are available (https://www.cdc. gov/std/ept/default.htm). For these methods, treatment and infection status of the partner can be verified and documented along with any co-occurring conditions (e.g., HIV infection or pregnancy) and health care access.

A DIS is a public health professional with applied expertise in client-centered interviews; partner services that include contact tracing, directly observed therapy, field specimen collection, and field investigation in outbreaks; and navigation of health care systems to ensure patient evaluation and treatment, among other areas (107). The position does not require a license, although persons with medical licenses sometimes serve in DIS positions. Relevant program areas include STD, HIV, tuberculosis, other communicable diseases, outbreak investigation, and emergency preparedness and response. DISs investigate STDs mandated by jurisdictional needs. Providers in health care settings are encouraged to develop relationships with their local health departments so that they can involve DISs in the cases routinely investigated on the basis on resources available in the jurisdiction and better inform their patients about DIS services.

Partner services recommendations are outlined (Box 4). Additional information on these recommendations is available (Supplementary Appendix 1, https://stacks.cdc.gov/view/cdc/82088).

\section{Evaluation of STD-Related Conditions}

Genital ulcer disease can be caused by syphilis, HSV, chancroid, granuloma inguinale, and lymphogranuloma venereum (LGV). The more common sexually transmitted causes of male urethritis syndrome can include gonorrhea, chlamydia, mycoplasma, trichomoniasis, and HSV. Diseases characterized by vaginal discharge as a result of vaginitis can include bacterial vaginosis, trichomoniasis, and candidiasis. The causes of epididymitis, pharyngitis, cervicitis, and pelvic inflammatory disease (PID) can include gonorrhea and chlamydia. Most genital warts are caused by nononcogenic HPV types. However, on occasion, oncogenic types can be found in genital warts. Proctitis can be caused by gonorrhea, LGV serovars of Chlamydia trachomatis, syphilis, and HSV. Ectoparasitic infections typically include pediculosis pubis and scabies. Systemic or dermatologic conditions compatible with or suggestive of an STD can include disseminated gonorrhea, neurosyphilis, ocular syphilis, condylomata lata, or palmar plantar syphilitic rash. STD-related conditions warrant prompt evaluation of signs and symptoms to make an accurate diagnosis and provide timely empiric treatment to prevent complications and onward transmission. Patients with a clinical presentation suggestive of an STD etiology (genital ulcer disease, urethritis, vaginal discharge, PID, epididymitis, pharyngitis, genital warts, proctitis, ectoparasitic infections, or certain systemic or dermatologic conditions) should be evaluated $(17,70,71)$.

Recommendations for the STD-related conditions that should be evaluated are summarized (Box 5). Additional information

BOX 4. Partner services recommendations for sexually transmitted diseases care in primary care and sexually transmitted diseases specialty care settings*

\section{STD care in primary care settings}

- The following partner services should be available as basic STD care services:

- Guidance regarding notification and care of sex partners

- EPT (where legal and where local or state jurisdictions do not prohibit by regulation) ${ }^{\dagger}$

- The following partner services could be available as a basic STD care service:

- Interactive counseling for partner notification

\section{STD care in STD specialty care settings}

- The following partner services should be available as specialized STD care services:

- Guidance regarding notification and care of sex partners

- Interactive counseling for partner notification

- EPT (where legal and where local or state jurisdictions do not prohibit by regulation) ${ }^{\dagger}$

- Health department DIS elicitation of sex partner information to identify those who might have been exposed and to identify patient follow-up needs $\$$

Abbreviations: DIS = disease intervention specialist; EPT = expedited partner therapy; STD = sexually transmitted disease.

* Primary care setting is defined as a place where patients are evaluated for various health conditions. STD specialty care setting is defined as a place where the focus is on providing patients with timely, comprehensive, confidential, and culturally sensitive STD care. STD care delivered in STD specialty care settings includes all care delivered in primary care settings.

$\dagger$ Information on legal status of EPT for each state is available at https://www.cdc.gov/std/ept/legal/default.htm.

$\S$ Partner services can be provided on site or by referral. 


\section{STD care in primary care settings}

- Evaluation (history and examination) for the following STD-related conditions should be available as basic

STD care services:

- Genital ulcer disease

- Male urethritis syndrome

- Vaginal discharge

- PID

- Genital warts

- Proctitis ${ }^{\dagger}$

- Ectoparasitic infections

- Pharyngitis

- Epididymitis

- Systemic or dermatologic conditions compatible with or suggestive of an STD etiology

\section{STD care in STD specialty care settings}

- Evaluation (history and examination) for the following STD-related conditions should be available as specialized STD care services:

- Genital ulcer disease

- Male urethritis syndrome

- Vaginal discharge

- PID

- Genital warts

- Proctitis ${ }^{\dagger}$

- Ectoparasitic infections

- Pharyngitis

- Epididymitis

- Systemic or dermatologic conditions compatible with or suggestive of an STD etiology

Abbreviations: PID = pelvic inflammatory disease; $\mathrm{STD}=$ sexually transmitted disease.

* Primary care setting is defined as a place where patients are evaluated for various health conditions. STD specialty care setting is defined as a place where the focus is on providing patients with timely, comprehensive, confidential, and culturally sensitive STD care. STD care delivered in STD specialty care settings includes all care delivered in primary care settings.

$\dagger$ Evaluation for proctitis might include visual examination of the anus, anorectal examination with a rectal swab, digital anorectal exam, or anoscopy. For specialized STD care, high-resolution anoscopy might be included.

on these recommendations is available (Supplementary Appendix 1, https://stacks.cdc.gov/view/cdc/82088).

\section{Laboratory}

Tests cleared by the U.S. Food and Drug Administration (FDA) are available for identifying STDs. Certain tests can be performed as point-of-care tests, either on site or through a clinical laboratory with rapid turnaround times. Providing results during the same clinic visit is ideal. Typically, these tests are waived by CLIA or are moderately complex. Use of commercially available NAATs for gonorrhea and chlamydia is cleared by FDA for genital tract specimens $(17,90)$.

Laboratory tests for identifying STDs are important for screening and diagnostic purposes. Screening tests are the only method for identifying asymptomatic infections. To improve rates of recommended screenings, primary care and STD specialty care providers can implement structural-level policy interventions in clinical settings, such as standing orders for the registration staff, express visits, specimen panels, and reflex testing. For patients, a sexual history and risk assessment can help determine whether a screening test is necessary. For patients with STD-related symptoms, both a physical examination and laboratory testing are needed along with a sexual history and risk assessment to determine the possible cause of symptoms and provide an opportunity for the diagnosis of other, unrecognized infections. In STD specialty care settings, same-day diagnosis and treatment are core functions for both health care and public health outcomes. With rapid laboratory results, treatment delays are reduced, resulting in fewer complications, less onward transmission of STDs, less time spent tracking and verifying treatment for those who fail to return after a positive test result, and more prudent use of antimicrobials based on less empiric treatment. STD specialty care settings should offer same-day diagnostic testing and treatment for patients with STD-related conditions and for sex partners of patients with a diagnosed sexually transmitted infection. Laboratory recommendations are outlined (Box 6).

\section{Treatment}

In settings where same-day treatment is available for patients with STD-related conditions and for sex partners of patients with a diagnosed STD, treatment should not be delayed while awaiting diagnostic test results. Delays in treatment might increase complications and contribute to transmission of infection in the community; and same-day treatment has numerous public health benefits. In an STD specialty care setting, same-day treatment should take place on site with the provision of a full course of appropriate medication. The first dose should be administered while the patient is in the clinic. 


\section{STD care in primary care settings} At the time of the patient visit

- The following general services, equipment, or tests should be available as basic STD care services at the time of the patient visit:
- Thermometer
$\circ \mathrm{pH}$ paper

- The following general services, equipment, or tests could be available as basic STD services with test results available during the patient visit:

- Phlebotomy

- Test for trichomoniasis ${ }^{\dagger}$

- Test for bacterial vaginosis $\$$

- Test for vulvovaginal candidiasis

- Urine dipstick

- Urinalysis with microscopy

- Test for pregnancy

- Test for HIV

\section{Clinical laboratory}

- The following tests should be available through clinical laboratory as basic STD care services:

- Urogenital NAAT for gonorrhea and chlamydia

- Extragenital (pharynx and rectum) NAAT for gonorrhea and chlamydia

- Quantitative nontreponemal serologic test for syphilis

- Treponemal serologic test for syphilis

- HSV viral culture or PCR

- HSV serology

- Fourth-generation antigen/antibody HIV test

- Oncogenic HPV NAATs with Pap smear

- nPEP and PrEP

- Serologic tests for hepatitis A, B, and C

- Test for pregnancy

- The following tests could be available through clinical laboratory as basic STD care services:

- Gram stain, methylene blue, or gentian violet stain for urethritis

- Gonorrhea culture

- Gonorrhea antimicrobial susceptibility testing**

- NAAT for trichomoniasis

\section{STD care in STD specialty care settings} At the time of the patient visit

- The following general services, equipment, or tests should be available as specialized STD care services at the time of the patient visit:

- Thermometer

- $\mathrm{pH}$ paper

- Phlebotomy

- Test for trichomoniasis ${ }^{\dagger}$

- Test for bacterial vaginosis $\$$

- Test for vulvovaginal candidiasis

- Urine dipstick

- Urinalysis with microscopy

- Test for pregnancy

- Gram stain, methylene blue, or gentian violet stain for urethritis

- On-site qualitative nontreponemal serologic test for syphilis

- The following general services, equipment, or tests could be available as specialized STD care services with test results available during the patient visit:

- Dark-field microscopy for syphilis

- Test for HIV

\section{Clinical laboratory}

- The following tests should be available through a clinical laboratory as specialized STD care services:

- Urogenital NAAT for gonorrhea and chlamydia

- Extragenital (pharynx and rectum) NAAT for gonorrhea and chlamydia

- Quantitative nontreponemal serologic test for syphilis

- Treponemal serologic test for syphilis

- HSV viral culture or PCR

- HSV serology

- Fourth-generation antigen/antibody HIV test

- Oncogenic HPV NAATs with Pap smear

$\circ$ nPEP and PrEP

- Serologic tests for hepatitis A, B, and C

- Gonorrhea culture

- Gonorrhea antimicrobial susceptibility testing**

- NAAT for trichomoniasis

Abbreviations: HIV = human immunodeficiency virus; HPV = human papillomavirus; HSV = herpes simplex virus; NAAT = nucleic acid amplification test; $\mathrm{nPEP}=$ nonoccupational postexposure prophylaxis; Pap $=$ Papanicolaou; $\mathrm{PCR}=$ polymerase chain reaction; $\operatorname{PrEP}=$ preexposure prophylaxis; $\mathrm{STD}=$ sexually transmitted disease.

* Primary care setting is defined as a place where patients are evaluated for various health conditions. STD specialty care setting is defined as a place where the focus is on providing patients with timely, comprehensive, confidential, and culturally sensitive STD care. STD care delivered in STD specialty care settings includes all care delivered in primary care settings.

$\dagger$ On-site test for trichomoniasis can include wet mount microscopy and OSOM Trichomonas.

$\S$ On-site test for bacterial vaginosis can include wet mount microscopy, OSOM BVBlue, and Affirm.

On-site test for vulvovaginal candidiasis can include wet mount microscopy.

** Access needs to be established for transport medium that adequately maintains the viability of Neisseria gonorrhoeae until the specimen reaches a laboratory (e.g., transport medium in transport container, transport system, or transport swab). Providers should contact their state or local health department if they have concerns about resistant $N$. gonorrhoeae infection or if assistance is required for culture and antimicrobial susceptibility testing. 
The STD Guidelines includes recommended regimens for treating STDs (17). An STD treatment guide app (STD Tx Guide), based on the STD Guidelines, is available free of charge for Apple and Android devices (https://www.cdc. gov/std/treatment-guidelines). Wall charts and pocket guides that include a summary of the guidelines for recommended medications, doses, and duration of therapy are also available at the link.

For STD care in primary care settings, the following treatments could be available on site: recommended medications for chlamydia and gonorrhea, medications used as first-line therapies for STD-related conditions (urethritis, cervicitis, PID, epididymitis, and proctitis), recommended medications for syphilis, emergency contraceptive pills, PrEP, nPEP, and provider-applied regimens for genital warts. If medications are not available on site, they should be available by prescription. Ideally, tracking systems to verify that the medications were picked up should be established for STD prescriptions. Providers might not receive reimbursement for oral medications without an on-site pharmacy. Providers can partner with local organizations, such as the local health department and community-based organizations, to procure oral medications. For syphilis treatment, providers can partner with local health departments to procure injectable medication.

For STD care in STD specialty care settings, recommended medications for common STDs and related conditions should be available on site with the exception of medications for bacterial vaginosis, candida vaginitis, urinary tract infections, ectoparasitic infections, and patient-applied regimens for genital warts. If medications are not available on site, they should be available by prescription. Sex partners should be treated as outlined in the STD Guidelines. Medications for sex partners of patients with gonorrhea, or both, should also be available on site and managed in accordance with state EPT laws and regulations. Alternative medications for chlamydia, gonorrhea, and syphilis, providerapplied regimens for genital warts, emergency contraceptive pills, and nPEP should be available on site. PrEP could be available on site. Specific guidance on provision of nPEP starter packs or a 28-day supply at initiation is available (https://stacks.cdc. gov/view/cdc/38856). Information on linkage to care is available (https://stacks.cdc.gov/view/cdc/44065). The treatment recommendations are listed (Box 7).

\section{Referral to a Specialist for Complex STD or STD-Related Conditions}

The STD Guidelines specifies conditions that should be managed through referral to a specialist (17). Referrals should be made to clinicians who have extensive specialized training or experience in diagnosing, treating, and providing follow up for complex STD cases. These providers can include adult and pediatric infectious disease clinicians, maternal-fetal medicine specialists, allergists, ophthalmologists, gastroenterologists, colorectal surgeons, urologists, oncologists, and other specialists. Services can be provided in different sites within a multispecialty practice or hospital system. Recommendations on referral to a specialist for complex STD or STD-related conditions are described (Box 8).

\section{Future Directions}

Research is needed to identify facilitators, barriers, and unintended consequences of implementing the recommendations for the specified STD or related clinical services in primary care and specialized STD care settings. High-priority research includes studies to quantify the impact of on-site or point-of-care services on patient compliance and health outcomes in various provider settings and patient populations.

\section{Conclusion}

The recommendations in this report contribute to improved STD care by defining the STD or related clinical services that should be available in primary care and STD specialty care settings. Specialized STD care focuses on the delivery of timely, comprehensive, confidential, and culturally sensitive STD clinical services. Specialized STD care also preferably includes on-site immediate diagnosis (e.g., Gram stain or other stains for urethritis or stat nontreponemal serologic tests for syphilis) and on-site injectable antimicrobials to treat syphilis and gonorrhea. STD care in primary care settings might offer some of the same services as specialized STD care settings but, at a minimum, should encompass sexual history and risk assessment, screening, and treatment services. This guidance complements CDC's STD Guidelines and outlines services for providing quality STD clinical services in primary care and STD specialty care settings. CDC will update STD QCS recommendations as more evidence become available and new practice standards are implemented. 


\section{STD care in primary care settings \\ On site}

- Medications for the following could be available on site as basic STD care services:

- Gonorrhea $^{\dagger}$

- Chlamydia ${ }^{\dagger}$

- Cervicitis

- Nongonococcal urethritis ${ }^{\dagger}$

- Proctitis

- PID

- Epididymitis

- Syphilis $\$$

- PrEP

- nPEP

- Provider-applied regimens for genital warts

- Emergency contraceptive pills

\section{Prescription}

- All recommended medications for the following should be available by prescription as basic STD care services:

- EPT for gonorrhea and chlamydia**

- Herpes

- Trichomoniasis

- Bacterial vaginosis

- Vulvovaginal candidiasis

- UTI

- PrEP

$\circ$ nPEP

- Emergency contraceptive pills

- Patient-applied regimens for genital warts

- Ectoparasitic infections

\section{STD care in STD specialty care settings}

On site

- Medications for the following should be available on site as specialized STD care services:

- Gonorrhea

- Chlamydia

- Cervicitis

- Nongonococcal urethritis

- Proctitis

- PID

$\circ$ Epididymitis

- Syphilis

$\circ$ nPEP

- Provider-applied regimens for genital warts

- Emergency contraceptive pills

- EPT for gonorrhea and chlamydia**

- Herpes

- Trichomoniasis

- Medications for the following could be available on site as specialized STD care services:

- Bacterial vaginosis

- Acute or new diagnosis of HIV care

- PrEP

- Persistent and recurrent cervicitis and nongonococcal urethritis

\section{Prescription}

- All recommended medications for the following should be available by prescription as specialized STD care services:

- Vulvovaginal candidiasis

- UTI

- PrEP

- Patient-applied regimens for genital warts

- Ectoparasitic infections

Abbreviations: $\mathrm{EPT}=$ expedited partner therapy; HIV = human immunodeficiency virus; $\mathrm{nPEP}=$ nonoccupational postexposure prophylaxis; PID $=$ pelvic inflammatory disease; PrEP = preexposure prophylaxis; STD = sexually transmitted disease; UTI = urinary tract infection.

* Primary care setting is defined as a place where patients are evaluated for various health conditions. STD specialty care setting is defined as a place where the focus is on providing patients with timely, comprehensive, confidential and culturally sensitive STD care. STD care delivered in STD specialty care settings includes all care delivered in primary care settings.

$\dagger$ Providers might not receive reimbursement for oral medications without an on-site pharmacy. Providers can partner with local organizations, such as the local health department and community-based organizations, to procure oral medications or refer patients to local organizations.

$\S$ Providers can partner with local health departments to procure injectable benzathine penicillin G or refer patients to local health department and verify treatment.

$\checkmark$ If emergency contraceptive pills are not available on site or by prescription, patients can be advised that levonorgestrel emergency contraceptive pills are available over the counter and ulipristal acetate emergency contraceptive pills are only available by prescription. Emergency contraceptive pills should be taken as soon as possible within 5 days of unprotected sex.

** Information on the legal status of EPT for each state is available at https://www.cdc.gov/std/ept/legal/default.htm. 


\section{Complex gonorrhea}

- Antimicrobial-resistant gonorrhea

- Cephalosporin or IgE-mediated penicillin allergy

- Suspected cephalosporin treatment failure

- Gonococcal conjunctivitis

- Disseminated gonococcal infection or gonococcal endocarditis or meningitis

- Gonococcal ophthalmia in infants

Complex chlamydial infections

- Chlamydial ophthalmia in infants

- Pneumonia in infants

- Persistent or recurrent epididymitis

- Persistent or recurrent cervicitis

- Cephalosporin or IgE-mediated penicillin allergy

- Suspicion of testicular torsion

\section{Complex syphilis}

- Primary, secondary, and latent syphilis in infants and children

- IgE-mediated penicillin allergy

- Tertiary syphilis

- Neurosyphilis

- Ocular or otic syphilis

- Syphilis during pregnancy with sonographic signs of fetal or placental syphilis

Complex vaginal discharge, trichomoniasis, and candidiasis

- Persistent vaginal discharge of unclear etiology

- Persistent or recurrent trichomoniasis

- IgE-mediated allergy to nitroimidazoles

- Recurrent vulvovaginal candidiasis in patients who remain culture-positive despite maintenance therapy

- Recurrent nonalbicans vulvovaginal candidiasis

\section{Complex PID}

- Cephalosporin or IgE-mediated penicillin allergy (quinolone resistant gonorrhea or antimicrobial susceptibility cannot be assessed)

- PID surgical complications (e.g., tubo-ovarian abscess)

Complex herpes

- Antiviral-resistant herpes infection

- Genital herpes contracted during third trimester of pregnancy

- Neonatal herpes

Viral hepatitis

- Hepatitis B infection

- Hepatitis C infection

Complex warts

- Cervical or intra-anal warts

- Atypical anogenital warts with high-grade squamous intraepithelial lesion on biopsy

Cervical intraepithelial neoplasia or cervical cancer

- Women with high- or low-grade squamous intraepithelial lesions on Pap smear

Complex ectoparasitic infections

- Crusted scabies in persons with HIV infection

Sexual assault

- HIV nPEP being considered

- STDs in children (if suspected possibility of sexual abuse)

HIV infection

- New diagnosis or establish link to care

Abbreviations: $\mathrm{HIV}=$ human immunodeficiency virus; $\mathrm{IgE}=$ immunoglobulin $\mathrm{E} ; \mathrm{nPEP}=$ nonoccupational postexposure prophylaxis; Pap = Papanicolaou; PID = pelvic inflammatory disease; PrEP = preexposure prophylaxis; STD = sexually transmitted disease.

\section{Conflict of Interest}

All authors have completed and submitted the International Committee of Medical Journal Editors form for disclosure of potential conflicts of interest. No potential conflicts of interest were disclosed.

\section{References}

1. Satterwhite CL, Torrone E, Meites E, et al. Sexually transmitted infections among US women and men: prevalence and incidence estimates, 2008. Sex Transm Dis 2013;40:187-93. https://doi. org/10.1097/OLQ.0b013e318286bb53

2. CDC. Sexually transmitted disease surveillance 2018. Atlanta: US Department of Health and Human Services, CDC; 2019. https://www. cdc.gov/std/stats18/default.htm 
3. Chesson HW, Gift TL, Owusu-Edusei K Jr, Tao G, Johnson AP, Kent CK. A brief review of the estimated economic burden of sexually transmitted diseases in the United States: inflation-adjusted updates of previously published cost studies. Sex Transm Dis 2011;38:889-91. https://doi.org/10.1097/OLQ.0b013e318223be77

4. Fleming DT, Wasserheit JN. From epidemiological synergy to public health policy and practice: the contribution of other sexually transmitted diseases to sexual transmission of HIV infection. Sex Transm Infect 1999;75:3-17. https://doi.org/10.1136/sti.75.1.3

5. Sexton J, Garnett G, Røttingen JA. Metaanalysis and metaregression in interpreting study variability in the impact of sexually transmitted diseases on susceptibility to HIV infection. Sex Transm Dis 2005;32:351-7. https://doi.org/10.1097/01.olq.0000154504.54686.d1

6. The Agreement of Brussels, 1924, respecting facilities to be given to merchant seamen for the treatment of venereal diseases: report of a study group. World Health Organ Tech Rep Ser 1958;39:1-63.

7. Fee E, Fox DM, eds. AIDS: The burden of history. Berkeley, CA: University of California Press; 1988.

8. Brandt AM. No magic bullet. A social history of venereal disease in the United States since 1880. New York, NY: Oxford University Press; 1985.

9. Institute of Medicine. The hidden epidemic: confronting sexually transmitted diseases. Washington, DC: National Academy Press; 1997.

10. Blackwell RL Jr. Health service utilization and stigma among HIVpositive men-who-have-sex-with men (MSM) in rural Appalachia [Dissertation]. Johnson City, TN: East Tennessee State University; 2014.

11. National Association of County and City Health Officials. Local health department job losses and program cuts: findings from the January 2012 survey. Washington DC: National Association of County and City Health Officials; 2012. https://foodpoisoningbulletin.com/wp-content/ uploads/Research-Brief-Final.pdf

12. National Coalition of STD Directors. Fact sheet: STD program capacity and preparedness in the United States: results of a national survey. Washington, DC: National Association of STD Directors; 2009. http://www.ncsddc.org/wp-content/uploads/2019/10/Fact-Sheet-STDProgram-Capacity-and-Preparedness-in-the-United-States-Re....pdf

13. Brackbill RM, Sternberg MR, Fishbein M. Where do people go for treatment of sexually transmitted diseases? Fam Plann Perspect 1999;31:10-5. https://doi.org/10.2307/2991551

14. Drainoni ML, Sullivan M, Sequeira S, Bacic J, Hsu K. Health reform and shifts in funding for sexually transmitted infection services. Sex Transm Dis 2014;41:455-60. https://doi.org/10.1097/ OLQ.0000000000000135

15. Pathela P, Klingler EJ, Guerry SL, et al; SSuN Working Group. Sexually transmitted infection clinics as safety net providers: exploring the role of categorical sexually transmitted infection clinics in an era of health care reform. Sex Transm Dis 2015;42:286-93. https://doi.org/10.1097/ OLQ.0000000000000255

16. New York State Department of Health. 2015 blueprint for achieving the goals set forth by Governor Cuomo to end the epidemic in New York State by the end of 2020. Albany, NY: New York State Department of Health; 2015. https://www.health.ny.gov/diseases/aids/ending_the_ epidemic/docs/blueprint.pdf

17. Workowski KA, Bolan GA; CDC. Sexually transmitted diseases treatment guidelines, 2015. MMWR Recomm Rep 2015;64(RR-3).

18. Aral SO, Hogben M, Wasserheit JN. STD-related health-care seeking and health service delivery [Chapter 92]. In: Holmes KK, Sparling P, Stamm WE, et al, eds. Sexually transmitted diseases. 4th ed. New York, NY: McGraw-Hill; 2008.

19. Cramer R, Leichliter JS, Gift TL. Are safety net sexually transmitted disease clinical and preventive services still needed in a changing health care system? Sex Transm Dis 2014;41:628-30. https://doi.org/10.1097/ OLQ.0000000000000187
20. Foglia G, Rhodes P, Goldberg M, St Louis ME. Completeness of and duration of time before treatment after screening women for Chlamydia trachomatis infections. Sex Transm Dis 1999;26:421-5. https://doi. org/10.1097/00007435-199909000-00001

21. Gift TL, Pate MS, Hook EW 3rd, Kassler WJ. The rapid test paradox: when fewer cases detected lead to more cases treated: a decision analysis of tests for Chlamydia trachomatis. Sex Transm Dis 1999;26:232-40. https://doi.org/10.1097/00007435-199904000-00010

22. Institute of Medicine. Crossing the quality chasm: a new health system for the 21st century. Washington, DC: Institute of Medicine; 2001. http://www.nationalacademies.org/hmd/Reports/2001/Crossing-theQuality-Chasm-A-New-Health-System-for-the-21st-Century.aspx

23. CDC. Program operations guidelines for STD prevention: medical and laboratory services. Atlanta, GA: US Department of Health and Human Services, CDC; 2001. https://www.cdc.gov/std/program/medlab.pdf

24. Fitch K, Bernstein SJ, Aguilar MD, et al. The RAND/UCLA appropriateness method user's manual. Santa Monica, CA: RAND Corporation; 2001. https://www.rand.org/pubs/monograph_reports/ MR1269.html

25. Andrews J, Guyatt G, Oxman AD, et al. GRADE guidelines: 14. Going from evidence to recommendations: the significance and presentation of recommendations. J Clin Epidemiol 2013;66:719-25. https://doi. org/10.1016/j.jclinepi.2012.03.013

26. Guerry SL, Bauer HM, Packel L, et al. Chlamydia screening and management practices of primary care physicians and nurse practitioners in California. J Gen Intern Med 2005;20:1102-7. https://doi. org/10.1111/j.1525-1497.2005.00240.x

27. Boekeloo BO, Marx ES, Kral AH, Coughlin SC, Bowman M, Rabin DL. Frequency and thoroughness of STD/HIV risk assessment by physicians in a high-risk metropolitan area. Am J Public Health 1991;81:1645-8. https://doi.org/10.2105/AJPH.81.12.1645

28. Wimberly YH, Hogben M, Moore-Ruffin J, Moore SE, Fry-Johnson Y. Sexual history-taking among primary care physicians. J Natl Med Assoc 2006;98:1924-9.

29. Melville SK, Arbona SI, Jablonski CL, et al. Risk assessment practices of Texas private practitioners for sexually transmitted diseases. Tex Med 2004;100:60-4.

30. Tao G, Irwin KL. Gonorrhea prevention and clinical care in the private sector: lessons learned and priorities for quality improvement. Sex Transm Dis 2006;33:652-62. https://doi.org/10.1097/01. olq.0000216030.65618.0e

31. Montaño DE, Phillips WR, Kasprzyk D, Greek A. STD/HIV prevention practices among primary care clinicians: risk assessment, prevention counseling, and testing. Sex Transm Dis 2008;35:154-66. https://doi. org/10.1097/OLQ.0b013e3181574d97

32. Tao G, Irwin KL, Kassler WJ. Missed opportunities to assess sexually transmitted diseases in U.S. adults during routine medical checkups. Am J Prev Med 2000;18:109-14. https://doi.org/10.1016/ S0749-3797(99)00139-7

33. Torkko KC, Gershman K, Crane LA, Hamman R, Barón A. Testing for chlamydia and sexual history taking in adolescent females: results from a statewide survey of Colorado primary care providers. Pediatrics 2000;106:e32. https://doi.org/10.1542/peds.106.3.e32

34. Ashton MR, Cook RL, Wiesenfeld HC, etal. Primary care physician attitudes regarding sexually transmitted diseases. Sex Transm Dis 2002;29:246-51. https://doi.org/10.1097/00007435-200204000-00011

35. Goyal MK, Witt R, Hayes KL, Zaoutis TE, Gerber JS. Clinician adherence to recommendations for screening of adolescents for sexual activity and sexually transmitted infection/human immunodeficiency virus. J Pediatr 2014;165:343-7. https://doi.org/10.1016/j.jpeds.2014.04.009

36. Fairley CK, Sze JK, Vodstrcil LA, Chen MY. Computer-assisted self interviewing in sexual health clinics. Sex Transm Dis 2010;37:665-8. https://doi.org/10.1097/OLQ.0b013e3181f7d505 
37. Sequeira S, Morgan JR, Fagan M, Hsu KK, Drainoni ML. Evaluating quality of care for sexually transmitted infections in different clinical settings. Sex Transm Dis 2015;42:717-24. https://doi.org/10.1097/ OLQ.0000000000000364

38. Henry-Reid LM, O'Connor KG, Klein JD, Cooper E, Flynn P, Futterman DC. Current pediatrician practices in identifying high-risk behaviors of adolescents. Pediatrics 2010;125:e741-7. https://doi. org/10.1542/peds.2009-0271

39. St Lawrence JS, Montaño DE, Kasprzyk D, Phillips WR, Armstrong K, Leichliter JS. STD screening, testing, case reporting, and clinical and partner notification practices: a national survey of US physicians. Am J Public Health 2002;92:1784-8. https://doi.org/10.2105/ AJPH.92.11.1784

40. Wimberly YH, Hogben M. Physicians' STD diagnosis and screening practices in the South. South Med J 2004;97:624-30. https://doi. org/10.1097/00007611-200407000-00003

41. Hogben M, St Lawrence JS, Kasprzyk D, et al. Sexually transmitted disease screening by United States obstetricians and gynecologists. Obstet Gynecol 2002;100:801-7.

42. Meyerson BE, Navale SM, Gillespie A, Ohmit A. Routine HIV testing in Indiana community health centers. Am J Public Health 2015;105:91-5. https://doi.org/10.2105/AJPH.2014.302203

43. Johnson CV, Mimiaga MJ, Reisner SL, VanDerwarker R, Mayer KH. Barriers and facilitators to routine HIV testing: perceptions from Massachusetts community health center personnel. AIDS Patient Care STDS 2011;25:647-55. https://doi.org/10.1089/apc.2011.0180

44. Haukoos JS, Hopkins E, Hull A, et al. HIV testing in emergency departments in the United States: a national survey. Ann Emerg Med 2011;58(Suppl 1):S10-6.e1-8. https://doi.org/10.1016/j. annemergmed.2011.03.033

45. Hammett TM, Kennedy S, Kuck S. National Survey of Infectious Diseases in Correctional Facilities: HIV and sexually transmitted diseases. Cambridge, MA: Abt Associates; 2007. https://www.ncjrs.gov/pdffiles1/ nij/grants/217736.pdf

46. Gallagher CA, Dobrin A. Can juvenile justice detention facilities meet the call of the American Academy of Pediatrics and National Commission on Correctional Health Care? A national analysis of current practices. Pediatrics 2007;119:e991-1001. https://doi.org/10.1542/ peds.2006-0959

47. McIntyre AF, Studzinski A, Beidinger HA, Rabins C. STD, HIV/AIDS, and hepatitis services in Illinois county jails. Sex Transm Dis 2009;36(Suppl):S37-40. https://doi.org/10.1097/ OLQ.0b013e31815e4167

48. Eubanks C, Lafferty WE, Kimball AM, MacCornack R, Kassler WJ. Privatization of STD services in Tacoma, Washington: a quality review. Sex Transm Dis 1999;26:537-42. https://doi. org/10.1097/00007435-199910000-00010

49. Meites E, Llata E, Braxton J, et al. Trichomonas vaginalis in selected U.S. sexually transmitted disease clinics: testing, screening, and prevalence. Sex Transm Dis 2013;40:865-9. https://doi.org/10.1097/ OLQ.0000000000000038

50. Dicker LW, Mosure DJ, Steece R, Stone KM. Testing for sexually transmitted diseases in U.S. public health laboratories in 2004. Sex Transm Dis 2007;34:41-6. https://doi.org/10.1097/01. olq.0000222708.70594.8e

51. Garrett TA, Davies-Cole J, Furness B. Laboratory capacity for antimicrobial susceptibility surveillance of Neisseria gonorrhoeaeDistrict of Columbia, 2007-2012. Sex Transm Dis 2015;42:413-6. https://doi.org/10.1097/OLQ.0000000000000304

52. Ahrens K, Bradbury KJ, Bauer HM, et al. Trends in the use of sexually transmitted disease diagnostic technologies in California, 1996-2003. Sex Transm Dis 2007;34:513-8. https://doi.org/10.1097/01. olq.0000253346.41123.7c
53. Burstein GR, Eliscu A, Ford K, et al. Expedited partner therapy for adolescents diagnosed with chlamydia or gonorrhea: a position paper of the Society for Adolescent Medicine. J Adolesc Health 2009;45:303-9. https://doi.org/10.1016/j.jadohealth.2009.05.010

54. Chen SY, Johnson M, Sunenshine R, England B, Komatsu K, Taylor M. Missed and delayed syphilis treatment and partner elicitation: a comparison between STD clinic and non-STD clinic patients. Sex Transm Dis 2009;36:445-51. https://doi.org/10.1097/ OLQ.0b013e3181a2aa95

55. Tabidze IL, Nicholson TF, Mikati T, Benbow N, Mehta SD. Adherence to Centers for Disease Control and Prevention gonococcal treatment guidelines among Chicago health care providers, 2011-2012. Sex Transm Dis 2015;42:422-8. https://doi.org/10.1097/OLQ.0000000000000310

56. Anschuetz G, Asbel L, Salmon ME, Johnson CC. Use of firstline treatment for Neisseria gonorrhoeae after treatment guideline changes. Sex Transm Dis 2014;41:64-6. https://doi.org/10.1097/ OLQ.0000000000000061

57. Schwebke JR, Sadler R, Sutton JM, Hook EW 3rd. Positive screening tests for gonorrhea and chlamydial infection fail to lead consistently to treatment of patients attending a sexually transmitted disease clinic. Sex Transm Dis 1997;24:181-4. https://doi. org/10.1097/00007435-199704000-00001

58. Bachmann LH, Richey CM, Waites K, Schwebke JR, Hook EW 3rd. Patterns of Chlamydia trachomatis testing and follow-up at a university hospital medical center. Sex Transm Dis 1999;26:496-9. https://doi. org/10.1097/00007435-199910000-00002

59. Fischer MA, Choudhry NK, Brill G, et al. Trouble getting started: predictors of primary medication nonadherence. Am J Med 2011;124:1081.e9-22. https://doi.org/10.1016/j.amjmed.2011.05.028

60. Hogben M, St Lawrence JS, Montaño DE, Kasprzyk D, Leichliter JS, Phillips WR. Physicians' opinions about partner notification methods: case reporting, patient referral, and provider referral. Sex Transm Infect 2004;80:30-4. https://doi.org/10.1136/sti.2003.004937

61. Golden MR, Whittington WL, Gorbach PM, Coronado N, Boyd MA, Holmes KK. Partner notification for chlamydial infections among private sector clinicians in Seattle-King County: a clinician and patient survey. Sex Transm Dis 1999;26:543-7. https://doi. org/10.1097/00007435-199910000-00011

62. Rogers ME, Opdyke KM, Blank S, Schillinger JA. Patient-delivered partner treatment and other partner management strategies for sexually transmitted diseases used by New York City healthcare providers. Sex Transm Dis 2007;34:88-92. https://doi.org/10.1097/01. olq.0000225322.94613.c2

63. Packel LJ, Guerry S, Bauer HM, et al. Patient-delivered partner therapy for chlamydial infections: attitudes and practices of California physicians and nurse practitioners. Sex Transm Dis 2006;33:458-63. https://doi. org/10.1097/01.olq.0000219865.65253.29

64. Hogben M, McCree DH, Golden MR. Patient-delivered partner therapy for sexually transmitted diseases as practiced by U.S. physicians. Sex Transm Dis 2005;32:101-5. https://doi.org/10.1097/01. olq.0000151417.43230.18

65. Niccolai LM, Winston DM. Physicians' opinions on partner management for nonviral sexually transmitted infections. Am J Prev Med 2005;28:229-33. https://doi.org/10.1016/j.amepre.2004.10.009

66. Navale SM, Meyerson BE, Ohmit A, Gillespie A. Understanding sexually transmitted infection screening and management in Indiana community health centers. Sex Transm Dis 2014;41:684-9. https://doi.org/10.1097/ OLQ.0000000000000198

67. Introcaso CE, Rogers ME, Abbott SA, Gorwitz RJ, Markowitz LE, Schillinger JA. Expedited partner therapy in federally qualified health centers-New York City, 2012. Sex Transm Dis 2013;40:881-5. https:// doi.org/10.1097/OLQ.0000000000000045 
68. Arora S, Kalishman S, Dion D, et al. Partnering urban academic medical centers and rural primary care clinicians to provide complex chronic disease care. Health Aff (Millwood) 2011;30:1176-84. https://doi. org/10.1377/hlthaff.2011.0278

69. Yu YY, Frasure-Williams JA, Dunne EF, Bolan G, Markowitz L, Bauer HM. Chlamydia partner services for females in California family planning clinics. Sex Transm Dis 2011;38:913-8. https://doi. org/10.1097/OLQ.0b013e3182240366

70. World Health Organization. Guidelines for the management of sexually transmitted infections. Geneva, Switzerland: World Health Organization; 2003. https://apps.who.int/iris/bitstream/ handle/10665/42782/9241546263_eng.pdf;jsessionid=186B422D61 93AE7AB2AD0D38BCD6A5C2? sequence $=1$

71. British Association for Sexual Health and HIV. Standards for the management of sexually transmitted infections (STIs). London, England: Medical Foundation for AIDS \& Sexual Health; 2010. https://www. bashh.org/documents/2513.pdf

72. American College of Obstetrics and Gynecology. Well-woman recommendations. Washington, DC: American Congress of Obstetrics and Gynecology; 2019. https://www.acog.org/AboutACOG/ACOG-Departments/Annual-Womens-Health-Care/ Well-Woman-Recommendations

73. Braverman PK, Breech L; Committee on Adolescence. American Academy of Pediatrics. Clinical report-gynecologic examination for adolescents in the pediatric office setting. Pediatrics 2010;126:583-90. https://doi.org/10.1542/peds.2010-1564

74. Walker HK, Hall WD, Hurst JW. Clinical methods: the history, physical, and laboratory examinations. 3rd ed. Boston, MA: Butterworths; 1990.

75. Committee on Adolescence. Condom use by adolescents. Pediatrics 2013;132:973-81. https://doi.org/10.1542/peds.2013-2821

76. Fiore AE, Wasley A, Bell BP; Advisory Committee on Immunization Practices (ACIP). Prevention of hepatitis A through active or passive immunization: recommendations of the Advisory Committee on Immunization Practices (ACIP). MMWR Recomm Rep 2006;55(No. RR-7).

77. Mast EE, Weinbaum CM, Fiore AE, et al; Advisory Committee on Immunization Practices (ACIP). A comprehensive immunization strategy to eliminate transmission of hepatitis B virus infection in the United States: recommendations of the Advisory Committee on Immunization Practices (ACIP) part II: immunization of adults. MMWR Recomm Rep 2006;55(No. RR-16).

78. Markowitz LE, Dunne EF, Saraiya M, et al; CDC. Human papillomavirus vaccination: recommendations of the Advisory Committee on Immunization Practices (ACIP). MMWR Recomm Rep 2014;63(No. RR-5). Erratum in: MMWR Recomm Rep 2014;63:1182.

79. Meites E, Kempe A, Markowitz LE. Use of a 2-dose schedule for human papillomavirus vaccination - updated recommendations of the Advisory Committee on Immunization Practices. MMWR Morb Mortal Wkly Rep 2016;65:1405-8. https://doi.org/10.15585/mmwr.mm6549a5

80. Curtis KM, Jatlaoui TC, Tepper NK, et al. U.S. selected practice recommendations for contraceptive use, 2016. MMWR Recomm Rep 2016;65(No. RR-4). https://doi.org/10.15585/mmwr.rr6504a1

81. Committee on Adolescence. Emergency contraception. Pediatrics 2012;130:1174-82. https://doi.org/10.1542/peds.2012-2962

82. LeFevre ML; US Preventive Services Task Force. Behavioral counseling interventions to prevent sexually transmitted infections: U.S. Preventive Services Task Force recommendation statement. Ann Intern Med 2014;161:894-901. https://doi.org/10.7326/M14-1965

83. CDC. Recommendations for HIV prevention with adults and adolescents with HIV in the United States, 2014. Atlanta, GA: US Department of Health and Human Services, CDC; 2014. https://stacks.cdc.gov/view/ $\mathrm{cdc} / 44064$

84. Committee on Pediatric AIDS; Emmanuel PJ, Martinez J. Adolescents and HIV infection: the pediatrician's role in promoting routine testing. Pediatrics 2011;128:1023-9. https://doi.org/10.1542/peds.2011-1761
85. CDC. Preexposure prophylaxis for the prevention of HIV infection in the United States—2017 update: a clinical practice guideline. Atlanta, GA: US Department of Health and Human Services, CDC; 2017. https:// www.cdc.gov/hiv/pdf/risk/prep/cdc-hiv-prep-guidelines-2017.pdf

86. CDC. Updated guidelines for antiretroviral postexposure prophylaxis after sexual, injection drug use, or other nonoccupational exposure to HIV-United States, 2016. Atlanta, GA: US Department of Health and Human Services, CDC; 2016. https://stacks.cdc.gov/view/cdc/38856

87. Gavin L, Moskosky S, Carter M, et al; CDC. Providing quality family planning services: recommendations of CDC and the U.S. Office of Population Affairs. MMWR Recomm Rep 2014;63(No. RR-4).

88. CDC. Recommendations for HIV prevention with adults and adolescents with HIV in the United States, 2014: summary for clinical providers. Atlanta, GA: US Department of Health and Human Services, CDC; 2014. https://stacks.cdc.gov/view/cdc/44065

89. LeFevre ML; US Preventive Services Task Force. Screening for chlamydia and gonorrhea: U.S. Preventive Services Task Force recommendation statement. Ann Intern Med 2014;161:902-10. https://doi.org/10.7326/M14-1981

90. Papp JR, Schachter J, Gaydos CA, Van Der Pol B. Recommendations for the laboratory-based detection of Chlamydia trachomatis and Neisseria gonorhoeae-2014. MMWR Recomm Rep 2014;63(No. RR-2).

91. Bibbins-Domingo K, Grossman DC, Curry SJ, et al; US Preventive Services Task Force (USPSTF). Screening for syphilis infection in nonpregnant adults and adolescents: US Preventive Services Task Force recommendation statement. JAMA 2016;315:2321-7. https://doi. org/10.1001/jama.2016.5824

92. US Preventive Services Task Force. Screening for syphilis infection in pregnancy: U.S. Preventive Services Task Force reaffirmation recommendation statement. Ann Intern Med 2009;150:705-9. https:// doi.org/10.7326/0003-4819-150-10-200905190-00008

93. Moyer VA; US Preventive Services Task Force. Screening for HIV: U.S. Preventive Services Task Force recommendation statement. Ann Intern Med 2013;159:51-60. https://doi. org/10.7326/0003-4819-159-1-201307020-00645

94. Branson BM, Handsfield HH, Lampe MA, et al. Revised recommendations for HIV testing of adults, adolescents, and pregnant women in health-care settings. MMWR Recomm Rep 2006;55(No. RR-14).

95. US Preventive Services Task Force. Screening for hepatitis B virus infection in pregnancy: U.S. Preventive Services Task Force reaffirmation recommendation statement. Ann Intern Med 2009;150:869-73, W154. https://doi.org/10.7326/0003-4819-150-12-200906160-00011

96. Weinbaum CM, Williams I, Mast EE, et al. Recommendations for identification and public health management of persons with chronic hepatitis B virus infection. MMWR Recomm Rep 2008;57(No. RR-8).

97. Moyer VA; US Preventive Services Task Force. Screening for hepatitis C virus infection in adults: U.S. Preventive Services Task Force recommendation statement. Ann Intern Med 2013;159:349-57. https://doi.org/10.7326/0003-4819-159-5-201309030-00672

98. Smith BD, Morgan RL, Beckett GA, et al; CDC. Recommendations for the identification of chronic hepatitis $\mathrm{C}$ virus infection among persons born during 1945-1965. MMWR Recomm Rep 2012;61(No. RR-4).

99. Committee on Adolescence; Society for Adolescent Health and Medicine. Screening for nonviral sexually transmitted infections in adolescents and young adults. Pediatrics 2014;134:e302-11. https:// doi.org/10.1542/peds.2014-1024

100. CDC. Recommendations for partner services programs for HIV infection, syphilis, gonorrhea, and chlamydial infection. MMWR Recomm Rep 2008;57(No. RR-9). 
101. CDC. Expedited partner therapy in the management of sexually transmitted diseases: review and guidance. Atlanta, GA: US Department of Health and Human Services, CDC; 2006. https://www.cdc.gov/std/ treatment/eptfinalreport2006.pdf

102. Task Force on Community Preventive Services. Recommendations to increase testing and identification of HIV-positive individuals through partner counseling and referral services. Am J Prev Med 2007;33(Suppl):S88. https://doi.org/10.1016/j.amepre.2007.04.013

103. McClean H, Radcliffe K, Sullivan A, Ahmed-Jushuf I. 2012 BASHH statement on partner notification for sexually transmissible infections. Int J STD AIDS 2013;24:253-61. https://doi. org/10.1177/0956462412472804

104. Ferreira A, Young T, Mathews C, Zunza M, Low N. Strategies for partner notification for sexually transmitted infections, including HIV. Cochrane Database Syst Rev 2013;10:CD002843. https://doi. org/10.1002/14651858.CD002843.pub2
105. American Academy of Pediatrics. Statement of endorsement—expedited partner therapy for adolescents diagnosed with chlamydia or gonorrhea. Itasca, IL: American Academy of Pediatrics; 2009. https://pediatrics. aappublications.org/content/124/4/1264

106. CDC; Association of Public Health Laboratories. Laboratory testing for the diagnosis of HIV infection: updated recommendations. Atlanta, GA: US Department of Health and Human Services, CDC; 2014. https://stacks.cdc.gov/view/cdc/23447

107. Public Health Accreditation Board. Disease Intervention Specialist National Certification Project: final report to the Centers for Disease Prevention and Control. Alexandria, VA: Public Health Accreditation Board; 2017. http://phaboard.org/wp-content/uploads/PHABFinalExec-Summary_Web-1.pdf 


\section{Subject Matter Experts}

Experts on STD Care in Primary Care Settings: Kevin Ault, MD, American Congress of Obstetricians and Gynecologists (ACOG); Brandi Basket, DO, Federally Qualified Health Center (FQHC); Gale Burstein, MD, American Academy of Pediatrics (AAP), Society for Adolescent Health and Medicine (SAHM); Keith Davis, MD, American Academy of Family Physicians (AAFP); Loretta Gavin, PhD, Office of Population Affairs (OPA); Ronald Goldschmidt, MD, AIDS Education and Training Centers (AETC); Michelle Khan, MD, ACOG; Helena Kwakwa, FQHC; Kathy McNamara, National Association of Community Health Centers (NACHC); Susan Moskosky, MS, OPA; Ina Park, MD, Network of STD Prevention Training Centers (NNPTC); Dennis Schaberg, MD, ACP; Davis Smith, MD, American College Health Association (ACHA).

Experts on STD Care in STD Specialty Care Settings: Laura Bachmann, MD, NNPTC; Heidi Bauer, MD, National Coalition of STD Directors (NCSD); Jonathan Cohn, MD, Wayne State University Adult HIV/AIDS Program; Julia Dombrowski, MD, University of Washington/Seattle King County; Edward Hook, MD, NNPTC; Kathy Hsu, MD, NNPTC; Kees Rietmeijer, MD, American STD Association; Ann Rompalo, MD, NNPTC; Bisan Salhi, MD, Association of Emergency Physicians; Stephanie Taylor, MD, Louisiana State University Health School of Medicine; Kimberly Workowski, MD, CDC and Emory University.

\section{Steering Committee Members}

Laura Bachmann, MD, NNPTC; Brandi Basket, DO, FQHC; Heidi Bauer, MD, NCSD; Gale Burstein, MD, AAP, SAHM; Jonathan Cohn, MD, Wayne State University Adult HIV/AIDS Program; Julia Dombrowski, MD, University of Washington/Seattle King County; Loretta Gavin, PhD, OPA; Ronald Goldschmidt, MD, AETC; Edward Hook, MD, NNPTC; Kathy Hsu, MD, NNPTC; Laura Makaroff, DO, Health Resources and Services Administration (HRSA); Kathy McNamara, RN, NACHC; Susan Moskosky, MS, OPA; Ina Park, MD, NNPTC; Kees Rietmeijer, MD, NNPTC; Ann Rompalo, MD, NNPTC; Dennis Schaberg, MD, ACP; William Smith, NCSD; Stephanie Taylor, MD, Louisiana State University Health School of Medicine; Kimberly Workowski, MD, CDC and Emory University.

\section{Other Invited Participants of the Consultation Meeting}

Michelle Allen, Georgia Department of Public Health (DPH); Paul Bloomquist, MD, Indian Health Service; Rupali Doshi, MD, HRSA; Victoria Green, MD, Emory University; Sanjay Lall, MD, Blue Cross Blue Shield of Georgia; Laura Makaroff, MD, HRSA.

\section{Peer Reviewers}

Barry Bennett, MD, Idaho Falls, Idaho; Rick Wherry, MD, Dahlonega, Georgia; Mary Campagnolo, MD, Bordentown, New Jersey; Dom Casablanca, MD, Shelton, Connecticut.

\section{Advisory Committee on HIV, Viral Hepatitis, and STD Prevention and Treatment (CHAC)}

Richard Aleshire, MSW, Washington State Department of Health; Jean Anderson, MD, Johns Hopkins Medical Institutions; Marvin Belzer, MD, University of Southern California Keck School of Medicine; Peter Byrd, peer educator and advocate; Dawn Fukuda, ScM, Massachusetts Department of Public Health; Debra Hauser, MPH, Advocates for Youth; Peter Havens, MD, Children's Hospital of Wisconsin; Devin Hursey, U.S. People Living with HIV Caucus; Amy Leonard, MPH, Legacy Community Health Services; Jorge Mera, MD, W.W. Hastings Indian Hospital; Jorge Mera, MD, W.W. Hastings Indian Hospital; Greg Millett, MPH, amfAR, The Foundation for AIDS Research; Susan Philip, MD, San Francisco Department of Public Health; Michael Saag, MD, University of Alabama at Birmingham School of Medicine, UAB Center for AIDS Research; Linda Scruggs, MHS, Ribbon Consulting Group; Bradley Stoner, MD, $\mathrm{PhD}$, Washington University School of Medicine; Lynn Taylor, MD, The Warren Alpert Medical School of Brown University.

\section{CHAC STD Work Group}

Co-Chairs: Susan Philip, MD, San Francisco DPH; Bradley Stoner, MD, PhD, Washington University School of Medicine.

Members: Jean Anderson, MD, Johns Hopkins Medical Institutions; Kevin Ard, MD, Massachusetts General Hospital/Fenway Institute; Deborah Belsky, MD, HRSA; Peter Byrd; Susan Cu-Uvin, MD, Brown Global Health Initiative, Providence/Boston Center for AIDS Research; Demetre Daskalakis, MD, New York City Department of Health and Mental Hygiene; Kim Erlich, MD, Mills Peninsula Medical Centers; John Fangman, MD, Medical College of Wisconsin; Charlene Flas, MD, Baylor College of Medicine; Travis Gayles, MD, PhD, District of Columbia Department of Health; Peter Haven, MD, Medical College of Wisconsin; Michael Mugavero, MD, University of Alabama Birmingham School of Medicine; Winston Tilghman, MD, County of San Diego Health and Human Services Agency; Matthew Weissman, MD, Community Healthcare Network; Karen Wendel, MD, Denver Public Health Department; Letha Healey, MD, HRSA.

\section{CDC Staff}

Faruque Ahmed, MD, PhD; Roxanne Barrow, MD; Diane Ballard, MD; Gail A. Bolan, MD; Sunity Chowdhury; Keith Davis; Jennifer Fuld, PhD; David Johnson, MPH; Angela Jones; David Ham, MD; Nadia Hawk; Matthew Hogben, PhD; Karen Hoover, MD; Jill Huppert, MD; Mahreen Karim; Brenda Kelley; Dan Lentine, MPH; Sheila McKenzie; Hilary Reno, MD, PhD; Raul Romaguera, DMD; Margie Scott-Cseh; Sheena Simmons, MPH; Phoebe Gates Thorpe, MD; Sharon Turner; Samantha Williams, PhD; Sharon Wong; Kimberly Workowski, MD. 

The Morbidity and Mortality Weekly Report (MMWR) Series is prepared by the Centers for Disease Control and Prevention (CDC) and is available free of charge in electronic format. To receive an electronic copy each week, visit MMWR at https://www.cdc.gov/mmwr/index.html.

Readers who have difficulty accessing this PDF file may access the HTML file at https://www.cdc.gov/mmwr/volumes/68/rr/rr6805a1.htm?s_ cid=rr6805a1_w. Address all inquiries about the $M M W R$ Series, including material to be considered for publication, to Executive Editor, $M M W R$ Series, Mailstop E-90, CDC, 1600 Clifton Rd., N.E., Atlanta, GA 30329-4027 or to mmwrq@cdc.gov.

All material in the MMWR Series is in the public domain and may be used and reprinted without permission; citation as to source, however, is appreciated. MMWR and Morbidity and Mortality Weekly Report are service marks of the U.S. Department of Health and Human Services.

Use of trade names and commercial sources is for identification only and does not imply endorsement by the U.S. Department of Health and Human Services.

References to non-CDC sites on the Internet are provided as a service to $M M W R$ readers and do not constitute or imply endorsement of these organizations or their programs by CDC or the U.S. Department of Health and Human Services. CDC is not responsible for the content of these sites. URL addresses listed in $M M W R$ were current as of the date of publication.

ISSN: 0149-2195 (Print) 